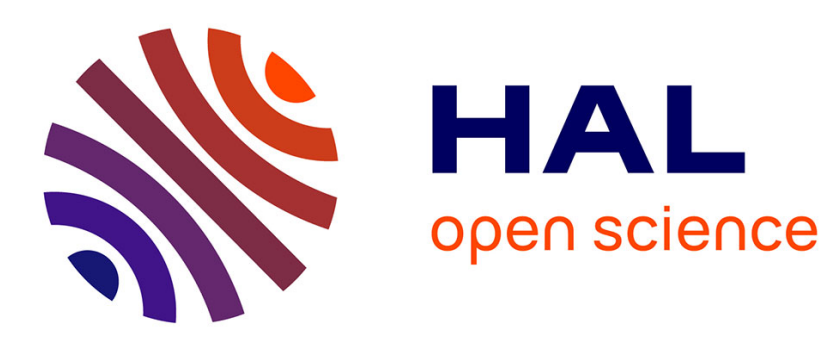

\title{
The propagation of $\mathrm{N}$ waves through turbulence: an experimental study
}

B. Lipkens

\section{To cite this version:}

B. Lipkens. The propagation of $\mathrm{N}$ waves through turbulence: an experimental study. Journal de Physique IV Proceedings, 1994, 04 (C5), pp.C5-1005-C5-1008. 10.1051/jp4:19945221 . jpa-00252907

\section{HAL Id: jpa-00252907 https://hal.science/jpa-00252907}

Submitted on 1 Jan 1994

HAL is a multi-disciplinary open access archive for the deposit and dissemination of scientific research documents, whether they are published or not. The documents may come from teaching and research institutions in France or abroad, or from public or private research centers.
L'archive ouverte pluridisciplinaire HAL, est destinée au dépôt et à la diffusion de documents scientifiques de niveau recherche, publiés ou non, émanant des établissements d'enseignement et de recherche français ou étrangers, des laboratoires publics ou privés. 


\title{
The propagation of $\mathrm{N}$ waves through turbulence: an experimental study
}

\author{
B. LIPKENS
}

Ecole Centrale de Lyon, Laboratoire de Mécanique des Fluides et d'Acoustique, URA 263

du CRNS, ECL, 36 Avenue Guy de Collongue, BP. 163, 69131 Ecully cedex, France

\begin{abstract}
: a model experiment to study the effect of atmospheric turbulence on sonic booms is reported. The model sonic booms are $\mathrm{N}$ waves produced by electric sparks, and the model turbulence is created by a plane jet. The important parameters are the waveform, peak pressure, and rise time because they determine the annoyance caused by sonic booms. Our experiment was designed so that the scale factor (approximately $10^{-4}$ ) relating the model turbulence to atmospheric turbulence was the same as that relating the model $\mathrm{N}$ waves to sonic booms. Results are reported for plane waves and are as follows. 1. The model experiment successfully simulates sonic boom propagation through the atmosphere. 2. Passage through turbulence almost always causes rise time to increase. 3 . Average rise time is always increased by turbulence. 4. Average peak pressure is always decreased by turbulence.
\end{abstract}

\section{INTRODUCTION}

Supersonic passage of an aircraft through the atmosphere creates a sonic boom. The sonic boom wavefront spreads out conically from an aircraft at an angle determined by the aircraft Mach number. In a steady atmosphere, the sonic boom measured at ground level has the general shape of an $\mathrm{N}$ wave, as is shown in Fig. 1 (a), [1]. The important characteristics of the waveform are peak pressure $\Delta p$, duration $T$, and rise time $\tau$, which is defined in this paper as the time required for the pressure to increase from $10 \%$ of $\Delta p$ to $90 \%$ of $\Delta p$. These are the main factors that determine the annoyance caused by the sonic booms.[2] The annoyance question provided the motivation for this work. The effect of atmospheric turbulence on sonic boom waveform, peak pressure, and rise time is the subject of this paper. Field measurements of sonic booms show that the ground signature is rarely an ideal $\mathrm{N}$ wave. A wide variety of distorted $\mathrm{N}$ waves is encountered (Fig. 1 (b)-(h), [1]), from spiked to rounded and even double and multiple peaked. It has long been accepted that turbulence is the cause of waveform variability, but the effect of turbulence on sonic boom rise time is more controversial. Several theories have been developed and model experiments performed to investigate the effect of turbulence on sonic boom waveform distortion and rise time. Some studies show a strong effect of turbulence on rise time, while others show none at all. A literature review is given in Ref. [3].

Our goal was to construct a model experiment to investigate the effect of turbulence on waveform, rise time, and peak pressure of $\mathrm{N}$ waves. The experiment design and apparatus are described in Sec. 2, the measurements and results are reported in Sec. 3. 

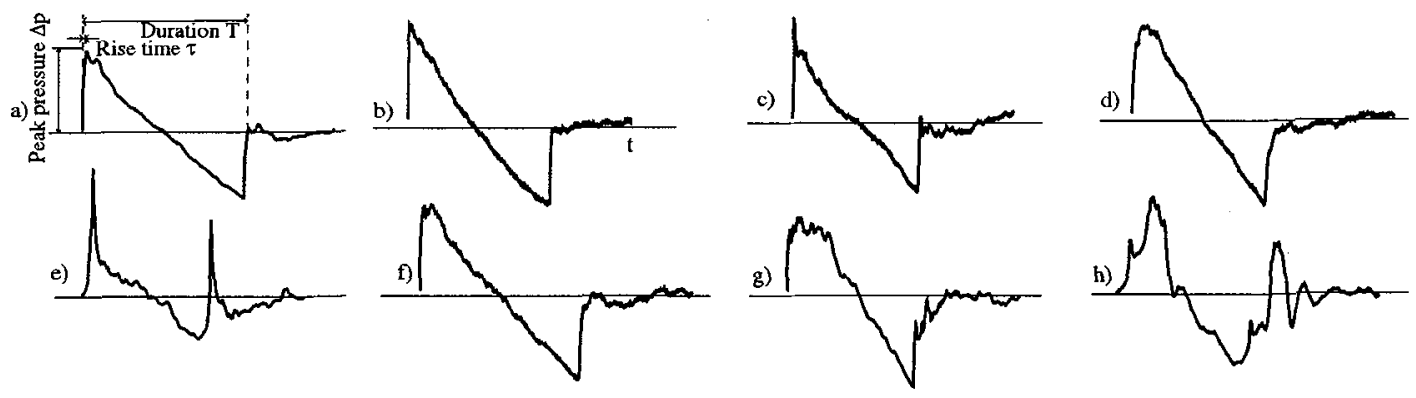

Figure 1: Sonic boom waveforms and terminology

\section{EXPERIMENT DESIGN AND APPARATUS}

In our model experiment the $\mathrm{N}$ waves are produced by electrical sparks and the turbulence was generated by a plane jet. An important requirement was that the model turbulence be scaled down from atmospheric turbulence by the same factor that the model $\mathrm{N}$ waves were scaled from sonic booms. Table I presents typical values of $\Delta P, T$, and $\tau$ for sonic booms and spark-produced $\mathrm{N}$ waves.

Table I. Typical values of $\tau, \Delta p$, and $T$ for sonic booms and spark-produced $N$ waves.

\begin{tabular}{lcc}
\hline \hline & Sonic boom & Spark-produced N wave \\
\hline$\Delta p$ & $30-200 \overline{\mathrm{Pa}}$ & $100-500 \mathrm{~Pa}$ \\
$\mathrm{~T}$ & $100-300 \mathrm{~ms}$ & $10-30 \mu \mathrm{s}$ \\
$\tau$ & $2-10 \mathrm{~ms}$ & $0.4-2 \mu \mathrm{s}$ \\
\hline \hline
\end{tabular}

It is observed that for both duration and rise time the scale factor relating the two waves is of order of 5,000 to 10,000 . The scale factor from Table I was used to design the model turbulence. Typical length scales of atmospheric turbulence were scaled down by this factor to obtain the design values for the model turbulence. To realize the model turbulent velocity field, we used a plane jet, generated by a fan, settling chamber, and a rectangular nozzle. The height of the nozzle was $0.25 \mathrm{~m}$; the width was controlled by a sliding door. The plane jet turbulence was measured by hot-wire anemometry and found to satisfy the design goals. The design and construction of the very wide band condenser microphone for measuring $\mathrm{N}$ waves with rise times as small as $0.5 \mu \mathrm{s}$ are described in Ref. [4]. To generate a plane wave, we placed the spark gap at the focus of a paraboloidal reflector. The reflected field off the paraboloid was planar enough over the measurement range to satisfy the needs of the model experiment.

\section{RESULTS}

The results for the plane wave measurements presented here demonstrate the similarity between propagation of the spark-produced $\mathrm{N}$ waves through the plane jet and propagation of sonic booms through the turbulent atmosphere. First, $100 \mathrm{~N}$ waves were fired and measured with quiet air. The fan was then switched on and a second set of $200 \mathrm{~N}$ wave signatures was captured. The width of the jet nozzle was $25.4 \mathrm{~mm}$, and the jet velocity was $31.3 \mathrm{~m} / \mathrm{s}$. The distance between the spark source and microphone was $0.45 \mathrm{~m}$, and the propagation path was $0.7 \mathrm{~m}$ downstream from the jet nozzle.

Some waveforms are shown in Fig. 2. The upper left signature is a reference waveform recorded in the absence of turbulence. The rest are typical waveforms recorded when the propagation path was through turbulence. An immediate conclusion is that they possess the same distortion that 
is observed for sonic boom signatures. The distortion is most pronounced near the bow and tail shocks. The fact that the tail shock usually has the same pattern of distortion as the bow shock is an indication that the turbulence is frozen during passage of the $\mathrm{N}$ wave. Variations in waveform from peaked to rounded and U-shaped are present. Double-peaked and multi-peaked waveforms are also evident.
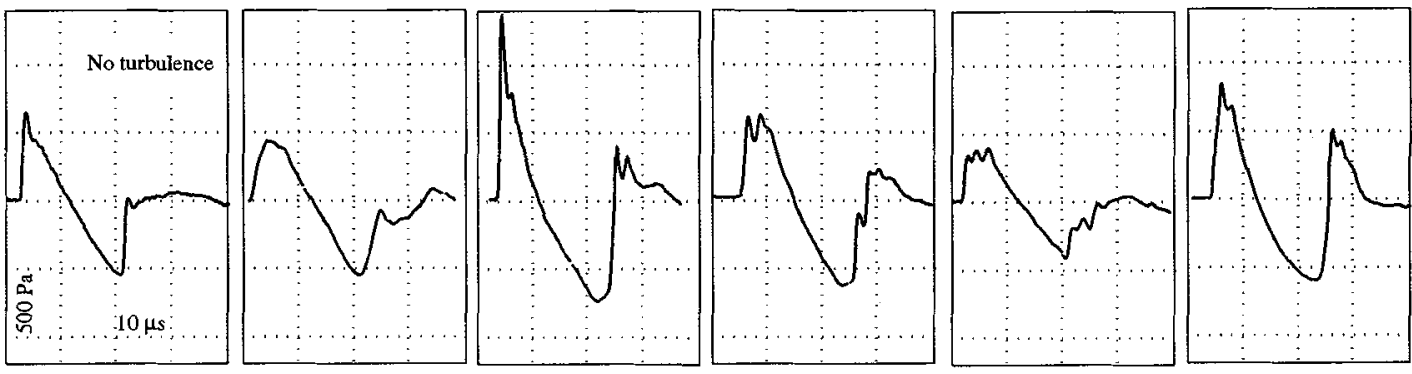

Figure 2: Waveforms of plane $\mathrm{N}$ waves; the left signature is a reference waveform. The abscissa is time (10 $\mu$ s per division), the ordinate is overpressure (500 Pa per division).

Figure 3 shows the data in the form of scatter diagrams, values of peak pressure and rise time as a function of measurement number in the run. Average values are indicated by a dashed horizontal line. Without turbulence, the $\mathrm{N}$ waves received were quite uniform. The variability of peak pressure and rise time became very large, however, when the turbulent jet was turned on. The mean and standard deviation of the data are given in Table II. The presence of turbulence caused the mean peak pressure to decrease by about $5 \%$ and the standard deviation to grow more than tenfold. Twelve runs with plane $N$ waves were done under varying conditions. The average peak pressure with the jet turned on was always found to be smaller than that with the jet turned off. The maximum decrease that occurred was $18 \%$. A related observation is that the number of spiked waveforms ( $\Delta p>\overline{\Delta p}_{\text {turb }}$, where $\overline{\Delta p}_{\text {turb }}$ is the average peak pressure with turbulence present) is about half the number of rounded waveforms $\left(\Delta p<\overline{\Delta p}_{\text {turb }}\right)$. The effect of turbulence on rise time was more spectacular: mean rise time nearly tripled and only a few $\mathrm{N}$ waves had a significantly lower rise time. The implication for sonic booms is important, since an increase in rise time causes a decrease in loudness associated with the boom. Finally, Table II shows that mean half duration increased about $7 \%$ while the mean arrival time decreased slightly. In other words, on average the $N$ waves were longer and arrived faster. The rise time cumulative probability function (Fig. 4) confirms that for plane $\mathrm{N}$ waves turbulence almost always (i. e. in $85 \%$ of the cases) increases the rise time. Some extremely high values of rise time were observed. More than $10 \%$ of the $\mathrm{N}$ waves have rise times more than seven times larger than that of the average no-turbulence rise time.
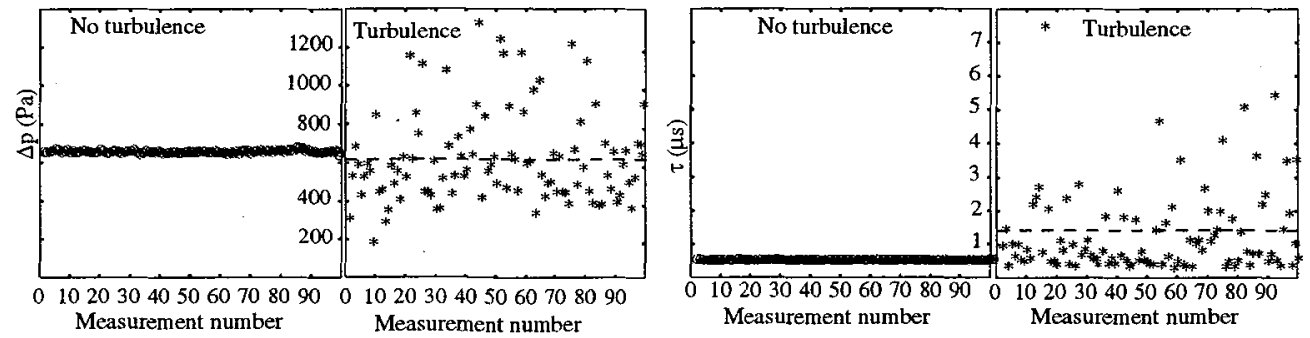

Figure 3: Values of rise time and peak pressure for 100 waves with and without turbulence. 


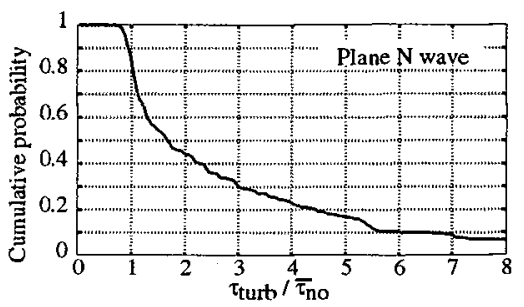

Figure 4: Rise time cumulative probability curve, $\bar{\tau}_{n o}$ is average rise time in quiet air.

Table II. Results of the propagation of plane $\mathrm{N}$ waves through plane jet turbulence.

\begin{tabular}{|c|c|c|c|c|c|c|c|c|}
\hline & \multicolumn{2}{|c|}{$\begin{array}{c}\tau \\
(\mu \mathrm{s})\end{array}$} & \multicolumn{2}{|c|}{$\begin{array}{c}\Delta p \\
(P a)\end{array}$} & \multicolumn{2}{|c|}{$\begin{array}{c}T \\
(\mu \mathrm{s})\end{array}$} & \multicolumn{2}{|c|}{$\begin{array}{c}t_{a r} \\
(\mu \mathrm{s})\end{array}$} \\
\hline & mean & $\sigma$ & mean & $\sigma$ & mean & $\sigma$ & mean & $\sigma$ \\
\hline no turb. & 0.506 & 0.010 & 651.4 & 6.0 & 10.642 & $0 . \overline{191}$ & 13.692 & 0.389 \\
\hline turb. & 1.450 & 1.450 & 620.7 & 228.4 & 11.317 & 1.286 & 12.786 & 2.471 \\
\hline
\end{tabular}

\section{SUMMARY AND CONCLUSIONS}

A model experiment is reported in which spark-produced $N$ waves propagate through a turbulent velocity field established by a plane jet. The waveform distortion suffered by sonic booms is reproduced, both in scale and in character, in the model experiment. Passage through the turbulence causes an enormous variability in rise time and peak pressure. Turbulence almost always increases the rise time. On average, the rise time increases up to a factor of three, while the peak pressure decreases by as much as $20 \%$. It is shown that turbulence causes a decrease in rise time for only a small percentage of $\mathrm{N}$ waves.

If the results of this model experiment were to be extrapolated to sonic booms, on average, a decrease in peak pressure combined with an increase in rise time would lower the loudness level associated with the booms. However, up to $10 \%$ of the waves have smaller rise times and higher peak pressures than the no-turbulence wave. The effect of these waves on the overall loudness needs further study.

\section{Références}

[1] R. A. Lee and J. M. Downing, "Sonic boom produced by United States Air Force and United States Navy aircraft: measured data," AL-TR-1991-0099, Armstrong Laboratory, WrightPatterson Air Force Base, Ohio (1991).

[2] A. Niedzwiecki and H. S. Ribner, "Subjective loudness of N-wave sonic booms," J. Acoust. Soc. Am. 64, 1622-1626 (1978).

[3] B. Lipkens, "Experimental and theoretical study of the propagation of $\mathrm{N}$ waves through a turbulent medium," Ph. D. dissertation, Department of Mechanical Engineering, University of Texas at Austin (1993).

[4] M. O. Anderson, "The propagation of a spherical N-wave in an absorbing medium and its diffraction by a circular aperture," Technical Rep. ARL-TR-74-25, Applied Research Laboratories, The University of Texas at Austin (1974) (AD 787 878). 